\title{
Fracture Properties of FRC Determined through Inverse Analysis of Wedge Splitting and Three-Point Bending Tests
}

\author{
Ingemar Löfgren ${ }^{1}$, Henrik Stang ${ }^{2}$ and John Forbes Olesen ${ }^{3}$
}

Received 10 May 2005, accepted 15 September 2005

\begin{abstract}
Fracture properties of five different steel fibre-reinforced concretes have been determined, using the wedge splitting test method (WST) and three-point bending tests (3PBT). Furthermore, for the WST method, two different specimen sizes have been investigated. Through inverse analyses, stress-crack opening $(\sigma-\mathrm{w})$ relationships have been determined for each mix and test method. Results from this investigation demonstrate the applicability of the WST method, show that inverse analysis can be used to determine stress-crack opening relationships, and the result demonstrate the effect of increased fibre content and the w/b-ratio. The major factor contributing to the differences in the determined stress-crack opening relationships is believed to be related to the variation in the number of fibres across the fracture plane. However, taking this into consideration, the inverse analyses indicate no systematic differences in the determined parameters between two WST specimen sizes, while the 3PBT seems to give slightly higher post-cracking stresses.
\end{abstract}

\section{Introduction}

During the past four decades, different methods have been used to characterize the tensile behaviour of fibrereinforced concrete (FRC): e.g. by measuring the flexural strength, as in the early work of Romualdi and Mandel (1964), or by determining the behaviour in terms of dimensionless toughness indices (as prescribed in ACI 544 and ASTM C 1018) to determine residual flexural strengths at prescribed deflections (see Gopalaratnam \& Gettu 1995, Barr et al. 1996, and RILEM TC 162-TDF 2002a). It can, however, be argued that, despite these methods, it is the lack of consistent design and test methods that has hampered a widespread utilization of FRC in structural applications. Moreover, inconsistent interpretation of test results, e.g. from bending tests, may lead to difficulties in distinguishing between the intrinsic properties of the material and the structural effects.

The addition of moderate amounts of short (discontinuous) fibres to concrete does not significantly affect the tensile strength or the modulus of elasticity. However, the fibres have a considerable impact on the tensile fracture behaviour and the energy dissipated during fracture. It is also generally accepted that fibre-reinforced concretes with low and moderate volume fractions, $V_{\mathrm{f}}$, of fibres can be regarded as a quasi-brittle material. Thus, the tensile fracture behaviour can be characterized by the

${ }^{1}$ Research Assistant, Department of Civil and Environmental Engineering, Chalmers University of Technology, Sweden.

E-mail: ingemar.lofgren@sem.chalmers.se

${ }^{2}$ Associate Professor, Department of Civil Engineering, Technical University of Denmark (DTU), Denmark.

${ }^{3}$ Associate Professor, Department of Civil Engineering, Technical University of Denmark (DTU), Denmark. tensile stress versus crack opening response (hereafter abbreviated as the $\sigma-w$ relationship), which is also associated with the so-called fictitious crack model originally suggested by Hillerborg (see Hillerborg et al. 1976). With the $\sigma-w$ relationship at hand it is possible to carry out design tasks based on non-linear fracture mechanics (see e.g. RILEM TC 162-TDF 2002b). In the fictitious crack model, the main parameters are the tensile strength, the modulus of elasticity, the fracture energy, and the shape of the $\sigma-w$ curve.

For regular concrete, the shape of the $\sigma-w$ curve does not vary too much (see Stang 1992 and Cornelissen et al. 1986) and for most practical applications it is usually sufficient to determine the fracture energy, $G_{\mathrm{F}}$, and select an appropriate $\sigma-w$ relationship. For FRC, on the other hand, the shape of the $\sigma$-w curves varies considerably depending on type and amount of fibres used, quality of the concrete, etc. (see e.g. Li et al. 1993). Furthermore, as pointed out by Hillerborg (1980), the complete fracture energy is of no interest since the stress-free crack opening, $w_{\mathrm{c}}$, occurs at very large crack openings for most FRCs, while for most concretes (without fibres) it is seldom larger than $0.3 \mathrm{~mm}$. Consequently, to completely characterize the mechanical behaviour of fibre-reinforced concrete in tension, it is necessary to determine the $\sigma-w$ relationship. The $\sigma-w$ relationship may be determined either directly, in a uniaxial tension test (UTT), or indirectly by performing an inverse analysis. In an inverse analysis the output from a test (typically a load-CMOD curve) is used as an input for the analysis, and the material parameters, which minimize the difference between the analytical curve and the test results, are determined.

RILEM technical committee 162-TDF, "Test and design methods for steel fibre-reinforced concrete", recently published recommendations for two test methods for steel fibre-reinforced concrete (SFRC); see RILEM-Committee-162-TDF (2001) and (2002a). The 
proposed test methods are a uniaxial tension test (UTT) and a three-point bending test (3PBT) on notched beams. The three-point bending test on notched beams is probably the most widespread method for determining the fracture properties; see RILEM TC-50 FMC (1985) for conventional concrete and RILEM TC 162-TDF (2002) for steel fibre-reinforced concrete. The UTT requires sophisticated testing equipment and is quite time-consuming to carry out, and it has been shown that the test result is affected by machine specimen interaction (see e.g. Østergaard 2003). Drawbacks with the 3PBT are that the specimen is quite large and heavy; furthermore, the method is not suited for evaluation of material properties in existing structures. The wedge splitting test (WST) method, originally proposed by Linsbauer and Tschegg (1986) and later developed by Brühwiler and Wittmann (1990), is an interesting test method since it does not require sophisticated test equipment; the test is stable and mechanical testing machines with a constant crosshead displacement can be used. Furthermore, a standard cube specimen is used, but the test can also be performed on core-drilled samples.

Researchers have used the WST method extensively, and recently there has been increased interest in it. The method has proved to be successful for the determination of fracture properties of ordinary concrete, at early age and later (see Østergaard 2003), and for autoclaved aerated concrete (Trunk et al. 1999). In addition, the method has been used for the study of fatigue crack growth in high-strength concrete (Kim and Kim 1999), and fracture behaviour of polypropylene fibre-reinforced concrete (Elser et al. 1996). For steel fibre-reinforced concrete, a small number of references can be found. Meda et al. (2001) used the WST method (with three specimen sizes) to determine a bi-linear stress-crack opening relationship through inverse analysis. Nemegeer et al. (2003) used the WST method to investigate the corrosion resistance of cracked fibre-reinforced concrete. However, in an experimental study conducted by Löfgren (2004) it was found that there may be problems with horizontal cracks, which was also found by Leite at el. (2004). Still, to the authors' knowledge there exist no proper recommendations regarding testing steel fibre-reinforced concrete by the WST method (specimen size, interpretation, etc).

In Fig. 1 the specimen geometry and loading procedure are clarified. The specimen is equipped with a groove (to be able to apply the splitting load) and a starter notch (to ensure the crack propagation). Two steel platens with roller bearings are placed partly on top of the specimen, partly into the groove, and through a wedging device the splitting force, $F_{\mathrm{sp}}$, is applied. During a test, the load in the vertical direction, $F_{\mathrm{v}}$, and the crack mouth opening displacement $(C M O D)$ are monitored.

The purpose of this paper is to demonstrate that the wedge splitting test (WST) method can be used to determine fracture properties of steel fibre-reinforced concrete and that with inverse analysis it is possible to determine the $\sigma-w$ relationship. In this study, experimental results from two different test methods are compared: the three-point bending test (3PBT) on notched beam, and the wedge splitting test (WST). Furthermore, for the wedge splitting test, two different specimen sizes have been investigated. Inverse analyses have been performed by using the finite element method (based on non-linear fracture mechanics) and an analytical model based on the cracked hinge model by Olesen (2001).

\section{Inverse analysis}

Inverse analysis - also referred to as parameter or function estimation - is achieved by minimizing the differences between calculated displacements and target displacements (e.g. CMOD) obtained from test results (see Fig. 2). In this manner, inverse analysis can be used to determine a $\sigma-w$ relationship from test results of methods like the 3PBT and the WST.

For regular concrete (i.e. without fibres), extensive research has been carried out to determine the best approach for inverse analysis and different strategies have been proposed. Of the available approaches, some define the shape of the $\sigma-w$ relationship as bi-linear (see e.g. Roelfstra and Wittmann 1986, Planas et al. 1999, Østergaard 2003, Bolzon et al. 2002, and Que and

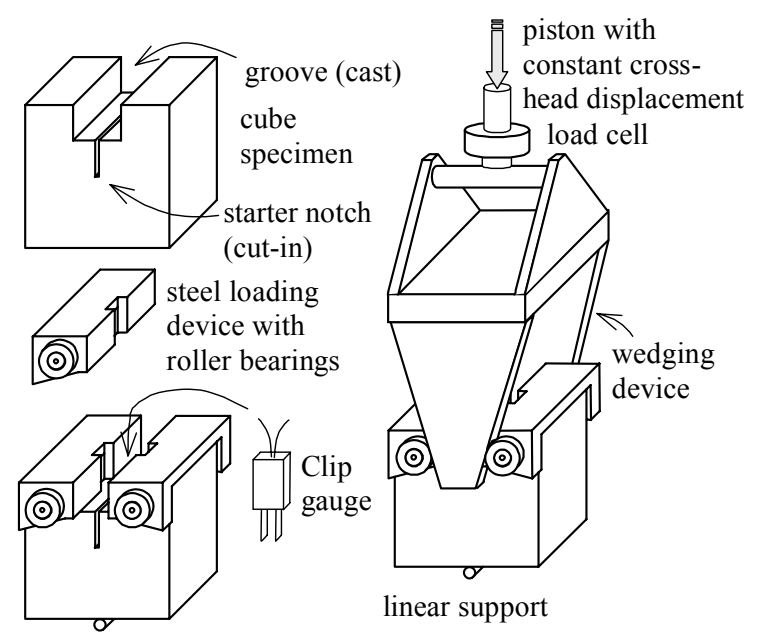

Fig. 1 Schematic view of the equipment and test set-up.

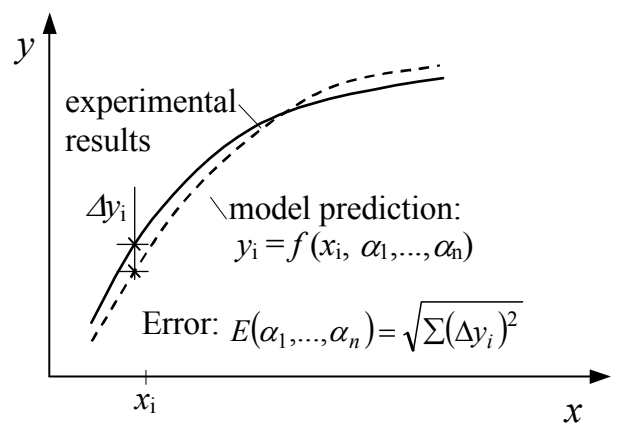

Fig. 2 Principle of inverse analysis. 
Tin-Loi 2002). In others, a poly-linear $\sigma-w$ relationship (see Fig. 3(b)) is used in conjunction with a stepwise analysis (see e.g. Kitsutaka 1997, Nanakorn and Horii 1996). The inverse analysis approach has also been used for FRC (see e.g. Rokugo et al. 1989, Uchida et al. 1995, Kooiman 2000, Meda et al. 2001, and Sousa et al. 2002). However, there are some problems associated with conducting inverse analysis on FRC. Some of these are: (1) the shape of the $\sigma-w$ relationship is not as well defined as for regular concrete, but varies depending on the mix constituents; (2) with increasing fibre volumes, it becomes difficult to distinguish between the effect of the tensile strength and the first slope of the $\sigma-w$ relationship; (3) the inverse problem is often ill-posed, i.e. there exists no unique solution. In addition, depending on the shape of the $\sigma-w$ relationship to be determined, a large number of parameters could be needed to describe it. If the $\sigma-w$ relationship is complex - requiring many parameters to be estimated - the iteration process becomes difficult and time-consuming. On the other hand, if the $\sigma-w$ relationship is too simple with only a few parameters needing to be estimated, it is not possible to converge to a good solution over the entire load-displacement curve.

To overcome some of the above problems, different approaches have been adopted. Kitsutaka (1995 and 1997) used an stepped analysis in combination with a poly-linear $\sigma-w$ relationship, which is an interesting approach, as the shape of the $\sigma-w$ relationship is not fixed. Uchida et al. (1995) utilised the stepped analysis technique to determine poly-linear $\sigma$ - $w$ relationships for various kinds of concrete. However, the approach relies on the assumption of uniform material properties over the entire height of a cross-section. As a consequence, the tensile strength, and the first part of the $\sigma-w$ relationship, will be determined for the first layer closest to the notch, and any variations in material properties across the height influence subsequent parts of the $\sigma-w$ relationship. Though, the influence of varying material properties diminishes with increasing $C M O D$, as the effect on the response decreases for parts further from the tip of the notch. The method may thus not provide an accurate value of the tensile strength (see Uchida and Barr 1998) and the initial part of the curve may be unreliable (see Planas et al. 1999). This problem was partly

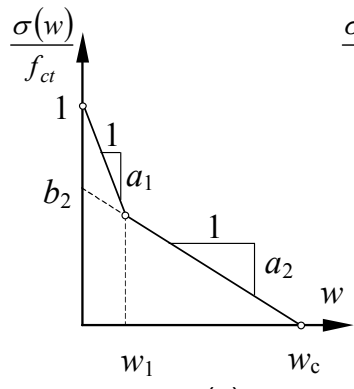

(a)

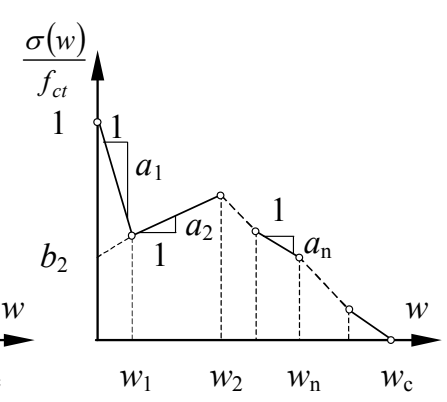

(b)
Fig. 3 (a) Bi-linear and (b) poly-linear $\sigma-w$ relationship. resolved by assuming the initial part of the softening diagram to be perfect plastic (see Uchida et al 1995). The assumption of uniform properties may well be justified for concrete without fibres, while for FRC it is quite likely that there will be variations due to non-uniform fibre orientation. These variations may not influence the tensile strength much, but a fibre bundle situated close to the notch can have a significant effect on the behaviour and influence the determination of the $\sigma-w$ relationship.

\subsection{Strategy for inverse analysis}

In this study, to average out the effects of the variations in fibre distribution and orientation between specimens, inverse analyses were conducted on the averaged load-CMOD curves (the average of all tested specimens from one mix) through use of a Matlab ${ }^{\circledR}$ program, developed at DTU by Østergaard (2003), which is based on the cracked hinge model by Olesen (2001) (see Østergaard and Olesen 2004). In the cracked hinge model it was assumed that the $\sigma-w$ relationship could be approximated by a bi-linear function (see Fig. 3(a)). The inverse analysis is performed in three phases: in phase I the modulus of elasticity is determined; in phase II the tensile strength and the first slope of the curve, $a_{1}$ in Fig. 3(a), is determined; and subsequently in phase III the other parameters $\left(a_{2}\right.$ and $\left.b_{2}\right)$ are determined. For each phase an optimization procedure is used to find a local minimum and the iteration continues, with globally re-running the optimization process for all phases, until the difference of the determined parameters is less than $1.0 \%$ between two subsequent iterations.

Inverse analyses were also conducted by using the finite element programme DIANA (see TNO 2002), with a poly-linear $\sigma-w$ relationship (see Fig. 3 (b)). In the FE-analyses, all elements outside the crack were assumed to have linear elastic and isotropic behaviour, and the crack was modelled as a discrete crack, using so-called non-linear interface elements. The interface elements can be considered as non-linear springs describing the Mode I fracture properties. Furthermore, plane stress conditions were assumed. In the FE-analyses, no automatic procedure was used for the inverse analyses; the $\sigma-w$ relationship was manually changed until the analysis result fitted the test result.

\section{Experimental program}

\subsection{Materials}

In total, five different concrete mixes were used in this investigation. The varied parameters were (see Table 1): the volume fraction of fibres, $V_{\mathrm{f}}$; the water binder ratio, $w / b$, of the concrete; and the fibre geometry (the length and diameter of the fibre). Hooked-end steel fibres (type Dramix $^{\circledR}$ ) were used: RC 65/60-BN (fibre-length $60 \mathrm{~mm}$, diameter $0.9 \mathrm{~mm}$ ) and RC 65/35-BN (fibre-length $35 \mathrm{~mm}$, diameter $0.55 \mathrm{~mm}$ ). 
Table 1 Concrete mix compositions.

\begin{tabular}{|l|c|ccccc|}
\hline Constituents & $\begin{array}{c}\text { Density } \\
{\left[\mathrm{kg} / \mathrm{m}^{3}\right]}\end{array}$ & $\begin{array}{c}\text { Mix 1 } \\
{\left[\mathrm{kg} / \mathrm{m}^{3}\right]}\end{array}$ & $\begin{array}{c}\text { Mix 2 } \\
{\left[\mathrm{kg} / \mathrm{m}^{3}\right]}\end{array}$ & $\begin{array}{c}\text { Mix 3 } \\
{\left[\mathrm{kg} / \mathrm{m}^{3}\right]}\end{array}$ & $\begin{array}{c}\text { Mix 4 } \\
{\left[\mathrm{kg} / \mathrm{m}^{3}\right]}\end{array}$ & $\begin{array}{c}\text { Mix 5 } \\
{\left[\mathrm{kg} / \mathrm{m}^{3}\right]}\end{array}$ \\
\hline CEM II/A-LL 52.5 R & 3100 & 260 & 260 & 360 & 360 & 360 \\
Fly ash & 2250 & - & - & 100 & 100 & 100 \\
Water & 1000 & 150 & 150 & 172 & 172 & 172 \\
Equivalent $w / b$-ratio & - & 0.58 & 0.58 & 0.42 & 0.42 & 0.42 \\
SIKA ViscoCrete 34 & 1090 & 0.4 & 0.953 & 0.4 & 0.4 & 0.4 \\
Aggregates: & & & & & & \\
$00-04 \mathrm{~mm}$ & 2535 & 822.6 & 794.1 & 745.4 & 745.4 & 744.3 \\
$04-08 \mathrm{~mm}$ & 2642 & 345.8 & 333.8 & 313.3 & 312.9 & 312.9 \\
$08-16 \mathrm{~mm}$ & 2637 & 700.7 & 676.5 & 635 & 634 & 634 \\
Fibres, $V_{\mathrm{f}}$ & 7800 & $0.5 \%$ & $1.0 \%$ & $0.5 \%$ & $1.0 \%$ & $1.0 \%$ \\
(Aspect ratio/Length) & & $(65 / 60)$ & $(65 / 60)$ & $(65 / 60)$ & $(65 / 60)$ & $(65 / 35)$ \\
\hline Measured air content & & $4.5 \%$ & $7.0 \%$ & $1.4 \%$ & $1.4 \%$ & $1.5 \%$ \\
\hline
\end{tabular}

\subsection{Three-point bending tests}

The three-point bending tests were conducted according to the recommendations of RILEM TC 162-TDF (2002a) (see Fig. 4) in an Instron 6025 universal testing machine with a capacity of $100 \mathrm{kN}$. The crack mouth opening displacement, $C M O D$, was measured at a distance of 8 $\mathrm{mm}$ from the bottom of the beam with an Instron clip gauge, having a $10 \mathrm{~mm}$ gauge length and a maximum travel of $5 \mathrm{~mm}$. The net load-point deflection was measured by two LVDTs. The tests were performed under $C M O D$ control. For each mix, five specimens were tested.

\subsection{Wedge splitting test}

For the WST method, two different specimen sizes were investigated: small specimens (Fig. 5(a) and large specimens Fig. 5(b)). The actual specimen sizes were chosen such that that they would constitute a representative volume similar to that of the 3PBT, but should also be practical for standard testing procedures (the specimens should not be too big or heavy). To avoid wall effect, the starter notch was sawn; and to ensure a vertical crack propagation, a $25 \mathrm{~mm}$ deep guide notch was cut on each side of the specimens according to Fig. 5(c) to produce a specimen with an effective thickness of 100 $\mathrm{mm}$. For each mix, six specimens were tested. The tests were performed under CMOD control in an Instron 6025 universal testing machine with a capacity of $100 \mathrm{kN}$. The $C M O D$ was measured with an Instron clip gauge, gauge

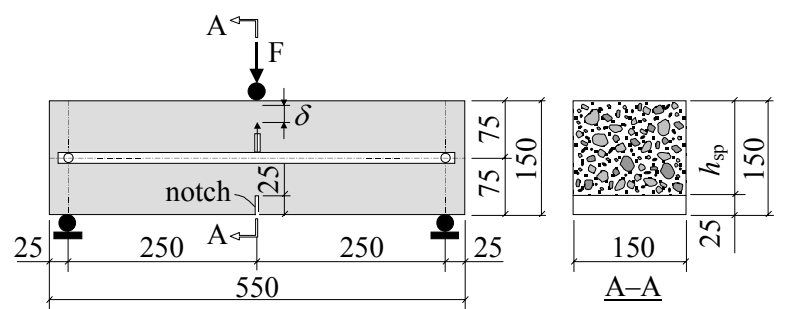

Fig. 4 Geometry of the three-point bending (3PBT) test according to RILEM TC 162-TDF.

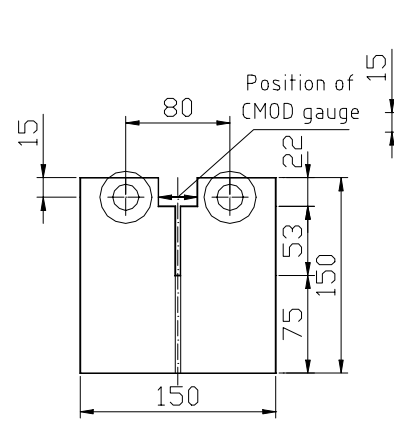

(a) Front view

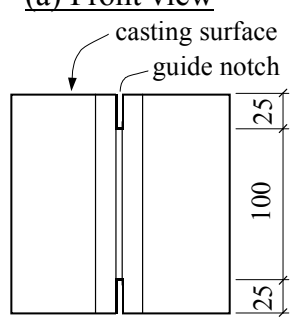

Specimens with guide notch

(c) Top view

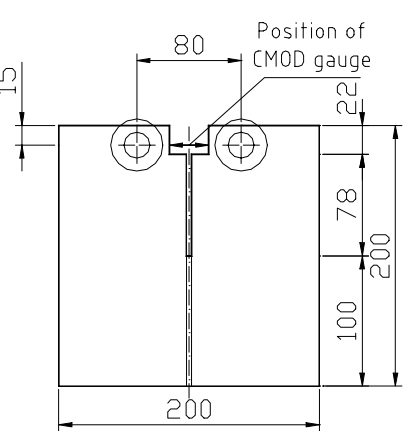

(b) Front view
Fig. 5 Geometry of the wedge splitting test specimens.

length $10 \mathrm{~mm}$ and maximum travel $5 \mathrm{~mm}$. In the tests, a wedge angle of $15^{\circ}$ was used and the roller bearings used were of the double-row-deep-groove type (manufactured by SKF, designation 4203 ATN9); see Fig. 6 for the experimental set-up.

\section{Test results}

\subsection{Three-point bending tests}

From the test results of the individual beams in a test series, average load-CMOD curves have been constructed; Fig. 7 shows the average load-CMOD curves for the mixes. In Fig. 7 it can be seen that, as the fibre volume increases, both the peak load and the post-peak load increase and the behaviour changes to deflection 

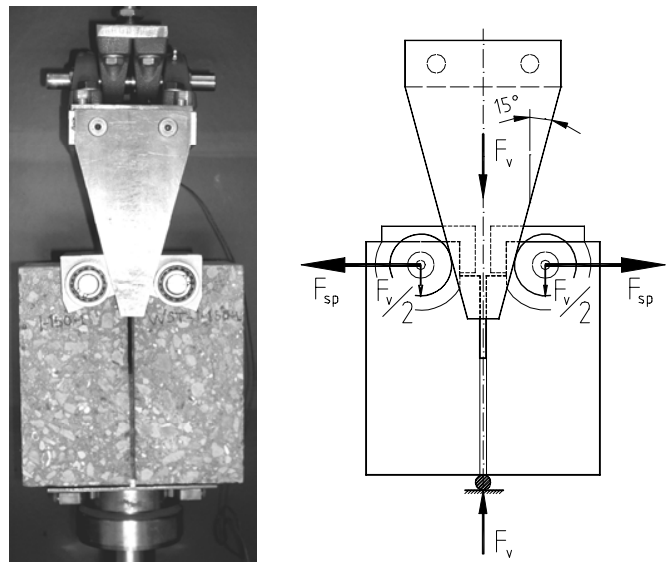

Fig. 6 Experimental set-up for the WST.

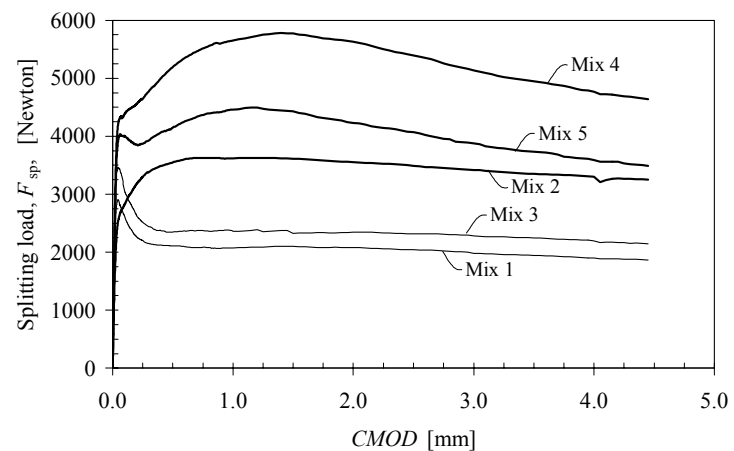

Fig. 8 Average splitting load-CMOD curves for the WST (small specimens).

hardening as opposed to softening and the peak-load occurs for larger CMODs. Furthermore, the w/b-ratio had a significant effect, and for the concretes with the lower $\mathrm{w} / \mathrm{b}$-ratio the peak- and the post-peak load increased and the behaviour changed to deflection hardening. The variability in the measured load was quite high; the coefficient of variance $(\mathrm{CoV})$ was $38 \%$ for Mix 1 and 2 but decreased as the fibre volume increased, with a $\mathrm{CoV}$ of $15 \%$ for Mix 3 and 4 and $10 \%$ for Mix 5 .

\subsection{Wedge splitting test}

Figure 8 shows the average splitting load-CMOD curves for the small WST specimens, and the corresponding results for the large WST specimens can be seen in Fig. 9. Similar to the 3PBT, in Fig. 7, it can be observed that the maximum splitting load, $F_{\mathrm{sp}}$, increases with the amount of fibres and that the behaviour changes from deflection softening to hardening. Furthermore, for the mixes with the lower w/b-ratio higher peak and post-peak loads can be observed and a change in behaviour to deflection hardening. The variability in the measured splitting load was overall slightly lower than for the 3PBT, the coefficient of variance $(\mathrm{CoV})$ varies between $12 \%$ and $25 \%$ for both specimen sizes.

\subsection{Fibre content}

The number of fibres crossing a crack has a significant

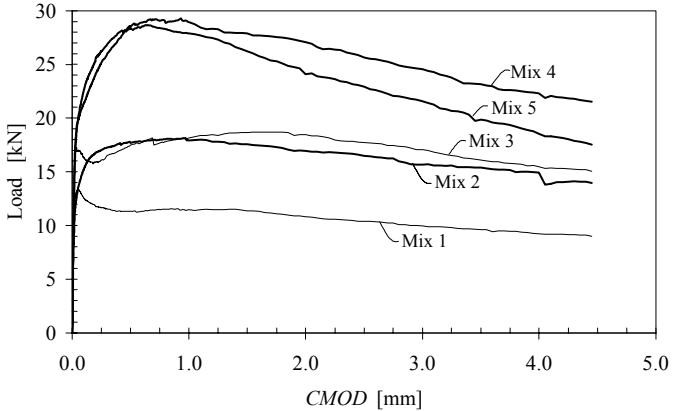

Fig. 7 Average load-CMOD curves for the 3PBT.

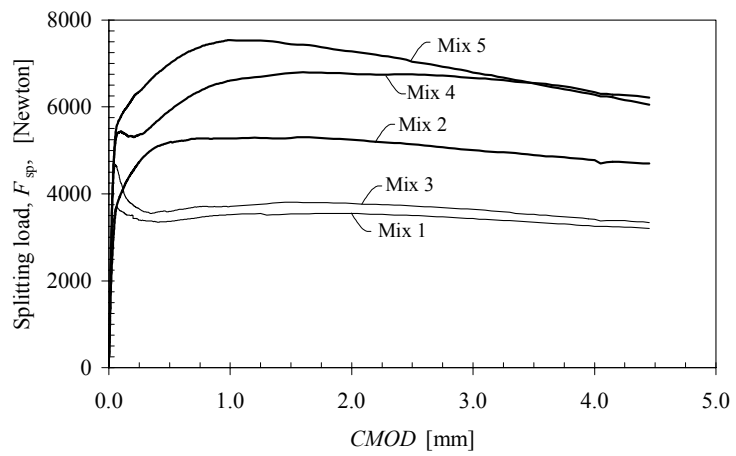

Fig. 9 Average splitting load-CMOD curves for the WST (large specimens).

influence on the toughness and the $\sigma$-w relationship. Therefore, the fibres crossing the fracture surface have been counted for all specimens and the fibre efficiency factor, $\eta_{\mathrm{b}}$, has been calculated. This factor defines the efficiency of bridging in terms of amount of fibres crossing a crack with respect to orientation effects. The theoretical fibre efficiency factor, $\eta_{\mathrm{b}}$, in a large volume is as follows (see e.g. Krenchel, 1975): for the 1-D case, $\eta_{\mathrm{b} .1 \mathrm{D}}=1$; for the $2-\mathrm{D}$ case, $\eta_{\mathrm{b} .2 \mathrm{D}}=2 / \pi\left(\eta_{\mathrm{b} .2 \mathrm{D}} \approx 0.64\right)$; and for the $3-\mathrm{D}$ case, $\eta_{\mathrm{b} .3 \mathrm{D}}=1 / 2$. Figure 10(a) presents the fibre efficiency factor, $\eta_{\text {b.exp }}$, as obtained in the specimens, and Fig. 10(b) shows its coefficient of variance $(\mathrm{CoV})$. The experimental fibre efficiency factor, $\eta_{\text {b.exp }}$, was calculated as:

$$
\eta_{\mathrm{b} . \exp }=\frac{N_{\mathrm{f} . \exp }}{V_{\mathrm{f}} / A_{\mathrm{f}}}
$$

where $N_{\text {f.exp }}$ is the number of fibres per unit area, $V_{\mathrm{f}}$ is the fibre volume fraction, and $A_{\mathrm{f}}$ is the cross-sectional area of a fibre.

The tendency is that the number of fibres is higher than the theoretical value for random 3-D orientation, sometimes closer to the 2-D case. For the short fibre (Mix 5) the difference is smaller when compared to the longer fibre. For the 3PBT, the number of fibres is closest to the theoretical value and shows the smallest scatter (average $\mathrm{CoV}$ is $16 \%$ ), except for Mix 1 . For the $3 \mathrm{PBT}$, the average fibre efficiency factor for mixes 1 to 4 is 0.6 ; this should be compared to a theoretical derived value, con- 


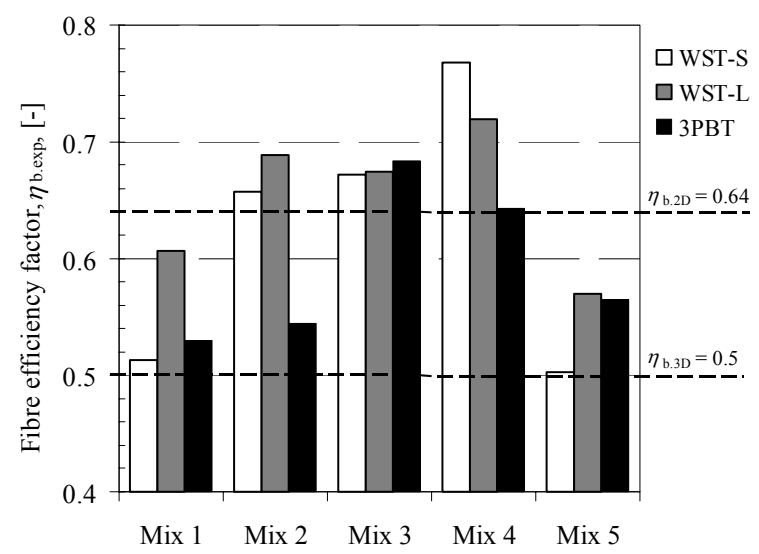

(a)

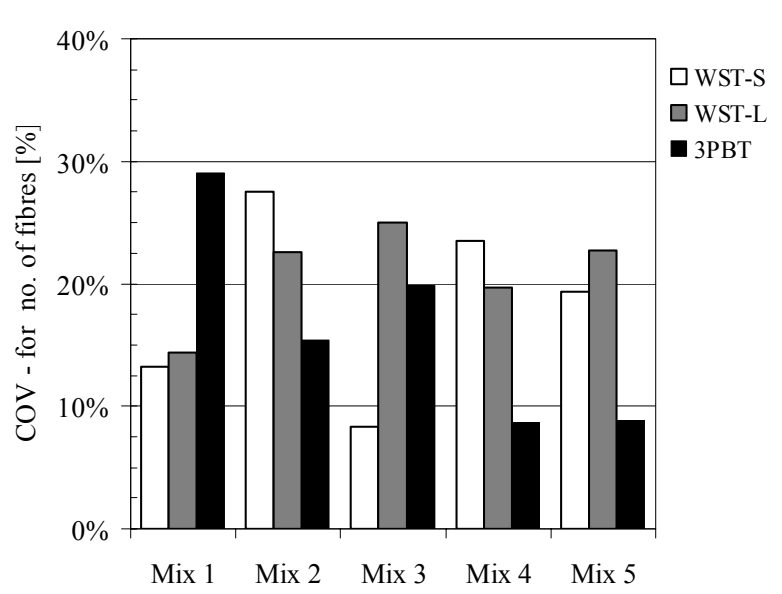

(b)

Fig. 10 (a) The fibre efficiency factor, $\eta_{\text {b.exp }}$, and (b) its coefficient of variance, CoV (white represents small WST specimens, dark grey for large WST specimens, and black for 3PBT specimens).

sidering the beam geometry and fibre length, of 0.58 (see Dupont 2003). When comparing the different specimens it can be seen that in some cases the WST specimens have more fibres than the 3PBT, while in others the amount of fibres are equal or less. For the small WST specimens, on average there seems to be a small increase in the number of fibres of 5\% compared to the 3PBT, and the scatter is also higher (average $\mathrm{CoV}$ is $18 \%$ ). For the large WST specimens, there is a small increase in the number of fibres of $10 \%$ compared to the $3 \mathrm{PBT}$, and the scatter is also higher (average $\mathrm{CoV}$ is $21 \%$ ). The number of fibres in the large WST specimens was for most mixes, except Mix 4, slightly higher compared to the smaller specimens, on average the increase was $6 \%$.

\section{Results of inverse analyses}

The comparisons between test results and inverse analyses are shown in Fig. 11 to Fig. 16. As can be seen, the FE-analyses show good agreement for all the specimens and mixes, while the bi-linear $\sigma-w$ relationship (used in the Matlab ${ }^{\circledR}$ program) gives good agreement for only some of the mixes. Evidently, the bi-linear relationship is not able to fit the test results for the specimens with a fibre volume fraction of $1 \%$.

\subsection{Stress-crack opening relationship}

The obtained $\sigma-w$ relationships are presented in Fig. 17 to Fig. 21 and in Table 2 the tensile strength is presented. The determined poly-linear $\sigma-w$ relationships have the following general shape: (1) an initial steep descending part; (2) a gradual ascending part; and (3) ends with a gradual descending part. The gradual ascending part is more pronounced for the mixes with the high fibre volume fraction.

Generally, the 3PBT seems to give a slightly higher tensile strength than does the WST method (see Table 2) and the variation between the two WST specimen sizes is small, less than $10 \%$. For mixes 1 and 2 , the agreement between the 3PBT and the WST is quite good (see Fig.

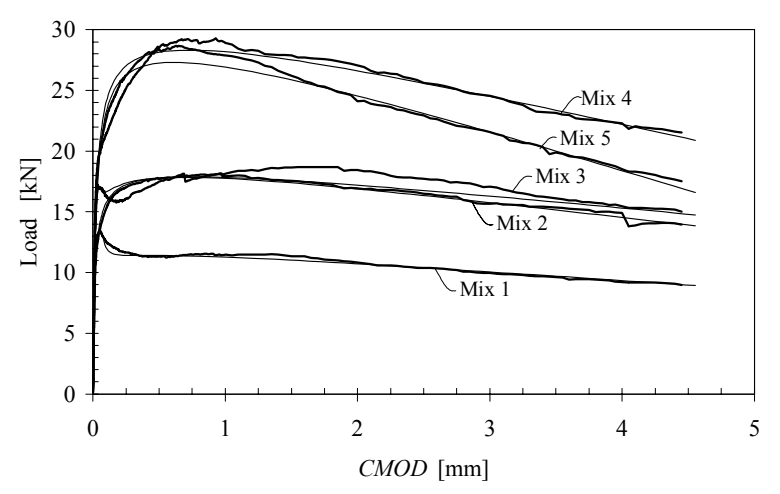

Fig. 11 Comparison of test results and inverse analyses using a bi-linear $\sigma-w$ relationship, for the 3PBT (thick lines represent the test results).

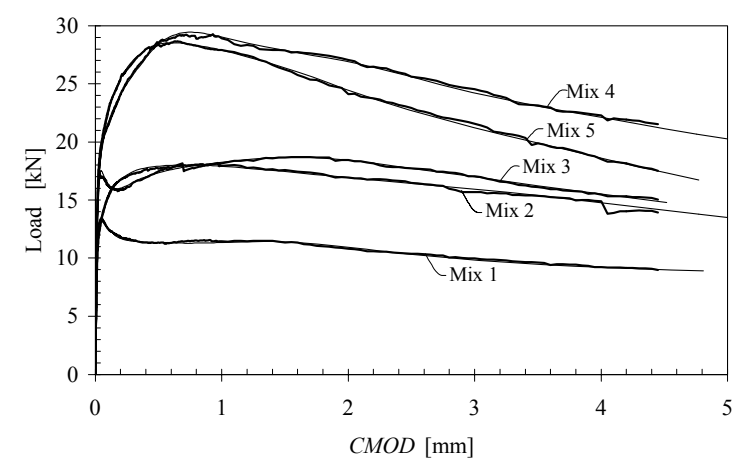

Fig. 12 Comparison of test results and FE-analyses for the 3PBT (thick lines represent the test results).

17 and Fig 18). For the other mixes the discrepancy is larger. With the bi-linear $\sigma-w$ relationship it is difficult to match the test results in detail; however, it seems that for larger crack openings the bi- and poly-linear $\sigma-w$ relationships give similar results. From the $\sigma-w$ relationships, the effect of an increased amount of fibres can be seen; 


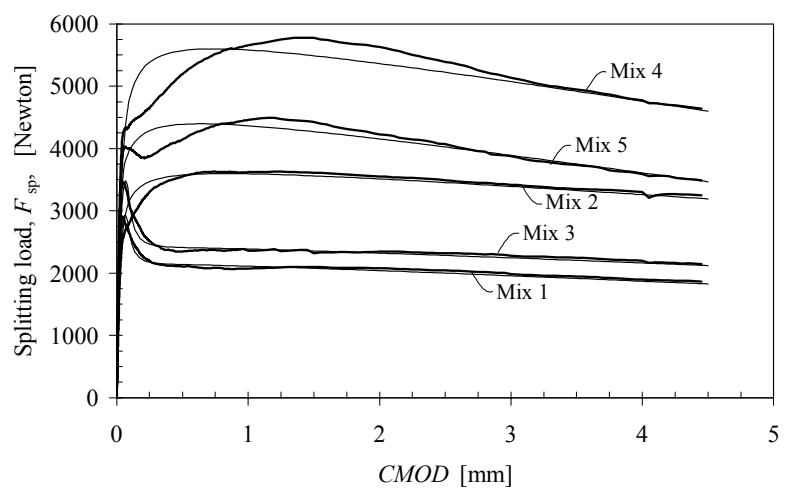

Fig. 13 Comparison of test results and inverse analyses using a bi-linear $\sigma-w$ relationship, for the small WST specimens (thick lines represent the test results).

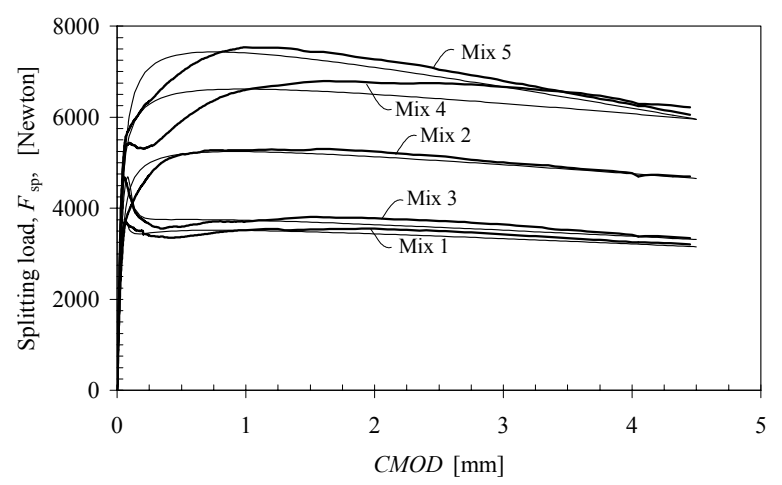

Fig. 15 Comparison of test results and inverse analyses using a bi-linear $\sigma-w$ relationship, for the large WST specimens (thick lines represent the test results).

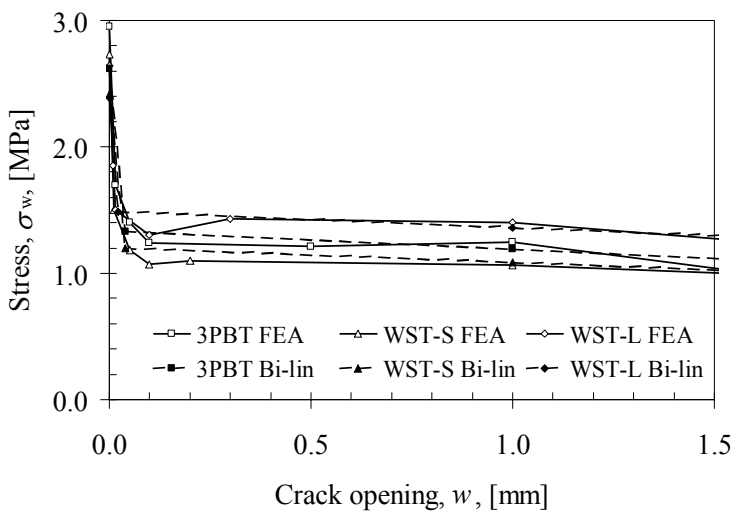

Fig. $17 \sigma$-w relationship for Mix 1.

compare Fig. 17 and Fig. 18 (Mix 1 compared to Mix 2), as well as Fig. 19 and Fig. 20 (Mix 3 compared to Mix 4). In the figures it is clear that the post-cracking stress (the residual stress) increases with increasing fibre content. The post-cracking stress is also higher for the concrete with the low w/b-ratio, probably a result of improved bond and a stronger matrix. Some of the differences in the $\sigma-w$ relationships are most likely to be related to the

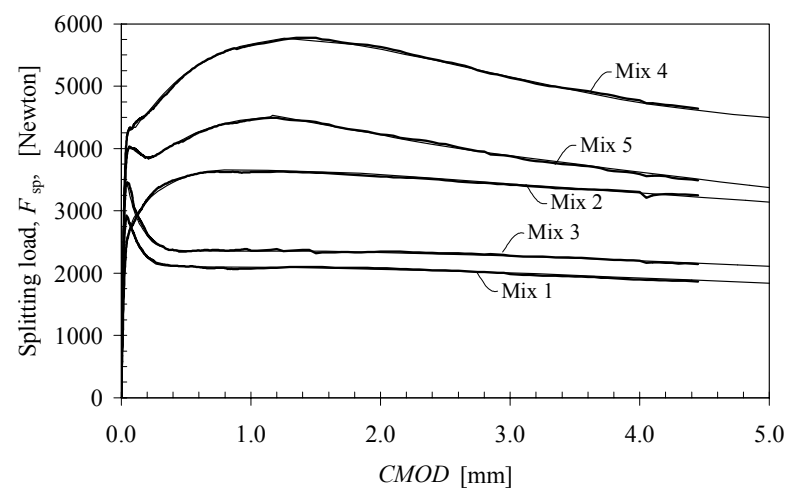

Fig. 14 Comparison of test results and FE-analyses for the small WST specimens (thick lines represent the test results).

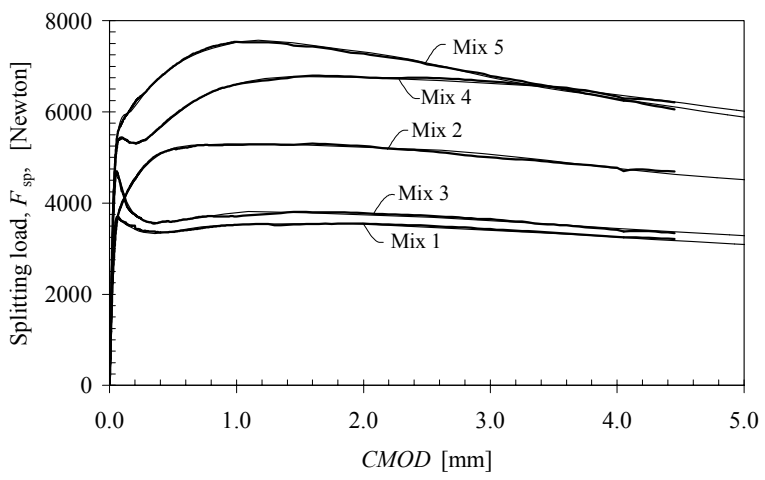

Fig. 16 Comparison of test results and FE-analyses for the large WST specimens (thick lines represent the test results).

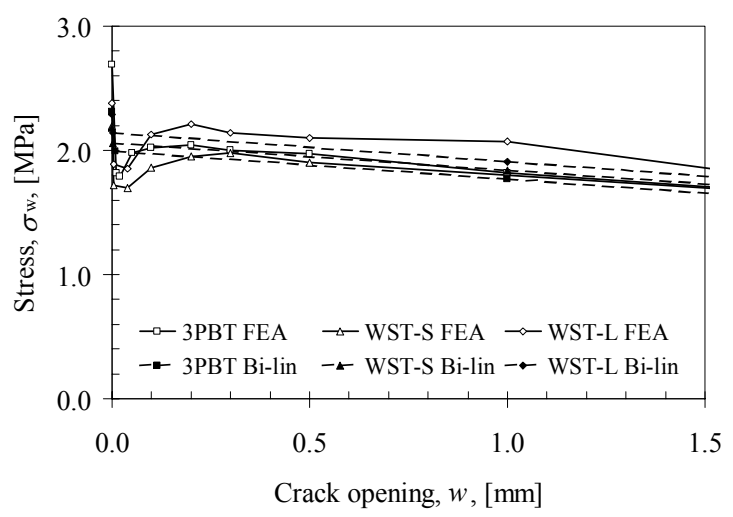

Fig. $18 \sigma-w$ relationship for Mix 2.

variation in fibre content and orientation, i.e. specimens with higher fibre content give higher post-cracking stresses (see Fig. 10 and Fig. 17 to Fig. 21). This variation in fibre content and orientation makes an exact comparison between the $\sigma-w$ relationships difficult. However, taking this into account it seems as the 3PBT give slightly higher post-cracking stresses (especially for the mixes with $V_{\mathrm{f}}=1.0 \%$ ). 
Table 2 Tensile strength (in MPa) determined with the different methods.

\begin{tabular}{|l|ccccc|}
\hline $\begin{array}{l}\text { Test } \\
\text { method }\end{array}$ & $\begin{array}{c}\text { Mix } \\
1\end{array}$ & $\begin{array}{c}\text { Mix } \\
2\end{array}$ & $\begin{array}{c}\text { Mix } \\
3\end{array}$ & $\begin{array}{c}\text { Mix } \\
4\end{array}$ & $\begin{array}{c}\text { Mix } \\
5\end{array}$ \\
\hline 3PBT & 2.95 & 2.69 & 3.62 & 3.74 & 3.72 \\
\hline WST-S & 2.73 & 2.20 & 3.28 & 3.68 & 3.45 \\
\hline WST-L & 2.64 & 2.38 & 3.58 & 3.57 & 3.53 \\
\hline
\end{tabular}

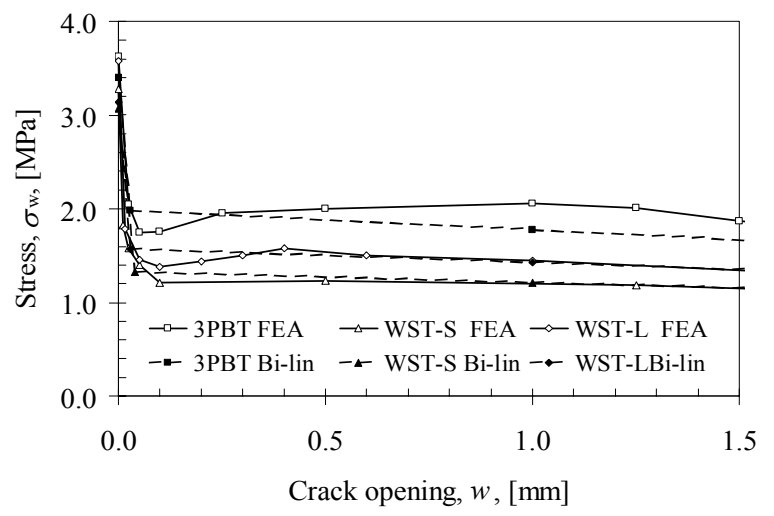

Fig. $19 \sigma-w$ relationship for Mix 3 .

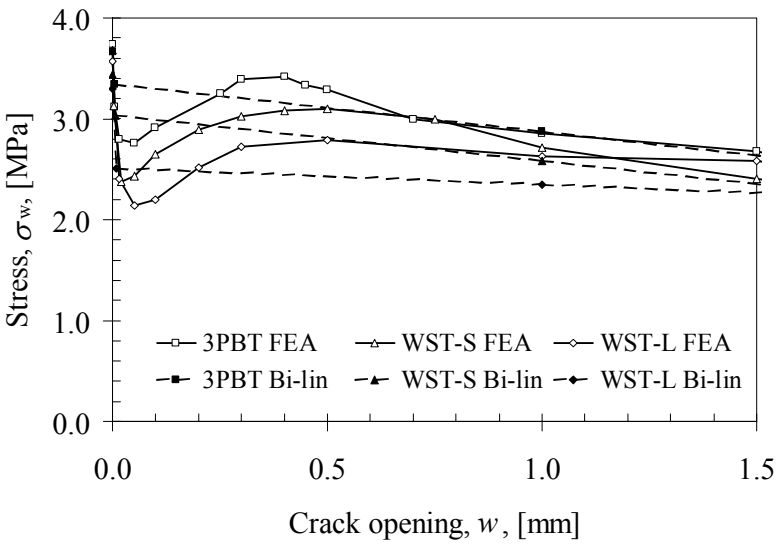

Fig. $20 \sigma-w$ relationship for Mix 4.

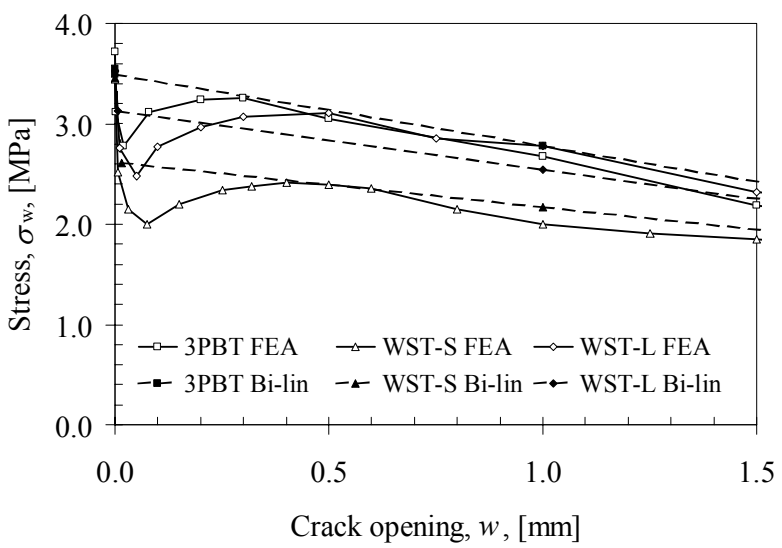

Fig. $21 \sigma$-w relationship for Mix 5.

\subsection{Relationship between CMOD and CTOD}

With both the 3PBT and the WST usually the CMOD is measured instead of a real crack opening - this is often due to measurement technique or specific test conditions. As can be seen in Fig. 22, while the $C M O D$ is measured at some distance from the tip of the notch, the crack tip opening displacement (CTOD) is the first crack opening in the specimen. When testing fibre-reinforced concrete it is normally difficult to run a test until the specimen has ruptured completely and, therefore it is necessary to specify a limit at which the test can be ended. The limit is usually related to the crack opening characterizing the service or ultimate limit state. As a result, a minimum displacement or $C M O D$ representing the specified crack openings has to be determined. Moreover, when performing inverse analysis, it may be also be necessary to continue the test past the minimum specified displacement or $C M O D$ in order to enhance the precision of the inverse analysis and get a representative result. The minimum required $C M O D$ may be determined by considering the relationship between the $C M O D$ and $C T O D$ together with the crack opening profile for the specimen, see Fig. 23. To facilitate such specifications for the WST-method, results from the FE-analyses have been used to determine the relationship between the $C M O D$ and $C T O D$, giving the following expressions (eq. 2 to eq. 4):

For the 3PBT (average value of Mix 1 to 5):

$$
C T O D=0.7889 \cdot C M O D-0.0098
$$

For the small WST (average value of Mix 1 to 5):

$$
C T O D=0.5530 \cdot C M O D-0.0071
$$

For the large WST (average value of Mix 1 to 5):

$$
C T O D=0.5349 \cdot C M O D-0.0087
$$

The crack opening profile at different $C M O D$ (obtained from the FE-analyses) can be seen in Fig. 23, and at large $C M O D$ s the crack profile is linear with a small compressive zone. This reveals that for the large WST

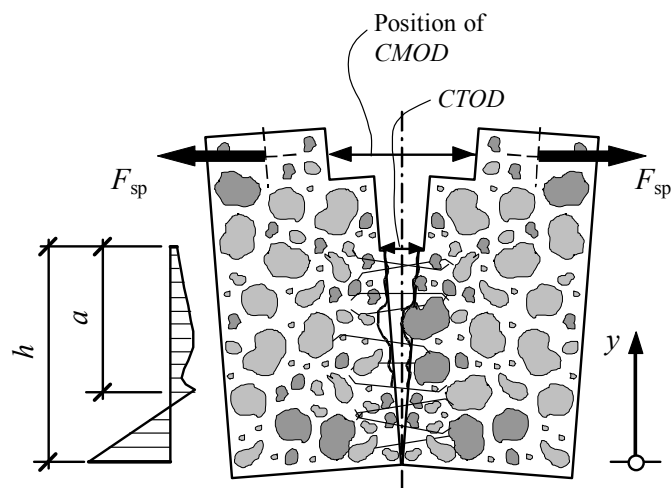

Fig. 22 Schematic view of stress distribution in a WST specimen and the definition of CMOD and CTOD $(h$ denotes the total length of the ligament and $a$ the length of the fictitious crack). 
specimen a $C M O D$ equal to $4.5 \mathrm{~mm}$ (used in this investigation) results in a $C T O D$ of $2.4 \mathrm{~mm}$ (using eq. 4). The $\sigma-w$ relationships were determined up to a crack opening of $1.5 \mathrm{~mm}$. In Fig. 23 it can be seen that at a depth of about $40 \%(y=60 \mathrm{~mm})$ of the specimen height the crack opening is $1.5 \mathrm{~mm}$ while at half the specimen height the crack opening is $1.2 \mathrm{~mm}$.

\section{Discussion}

The number of fibres crossing the fracture plane was more than the theoretical number for random 3-D orientation, which is no surprise as it has been found in a number of studies (see Dupont 2003 and Kooiman 2000) and since small-scale test specimens always influence the fibre orientation. Moreover, when comparing the average number of fibres for all mixes and specimen it seems as the beam specimens had fewer fibres $\left(\right.$ per $\left.\mathrm{cm}^{2}\right)$ than the WST specimens and that the small WST specimen had slightly fewer than the large. The reasons for this are not clear, and as the scatter was so high it is difficult to make any rigorous conclusions that can be statistically verified. The important point, however, is that the difference in fibre orientation between different test specimens and any small-scale test specimens and structural elements needs to be addressed if a $\sigma-w$ relationship obtained from inverse analysis is to be compared with other result or used for structural design. The differences in fibre content makes an exact comparison of the $\sigma-w$ relationships difficult; however, taking this into account it seems as the 3PBT give slightly higher post-cracking stresses (see Fig. 17 to Fig. 21). The reasons for the higher post-cracking stresses for the 3PBT could be a result of the diffused cracking (crack branching and two cracks in some cases) in some of the 3PBT specimens (see Fig. 24), which it is not possible to capture in the inverse analysis. The depth of the notch for the 3PBT was not sufficient to prevent multiple cracks when the fibre volume fraction was $1 \%$. This is an unwanted situation and it may be necessary to increase the notch depth when the volume fraction is $1 \%$ or higher. For the WST-specimens, the deep starter notch and the guide notch prevents this type of cracking and the crack is forced to propagate vertically with well-defined boundaries, a situation similar to a uni-axial tension test with notches. Furthermore, the situation with the guide notch corresponds well to the assumptions of a discrete crack in the FE-analysis.

The inverse analyses in this study were conducted on the averaged load-CMOD curves (the average of all tested specimens from one mix). The benefits of this are that it averages out the effects of any variations in fibre distribution and orientation between specimens, a representative curve are provided, and that only one analysis is required for determination of the $\sigma-w$ relationship. When performing the inverse analysis it was found that it is important that the first descending slope of the $\sigma-w$ relationship is estimated realistically - the slope should be steep - and that a sufficient number of points are used

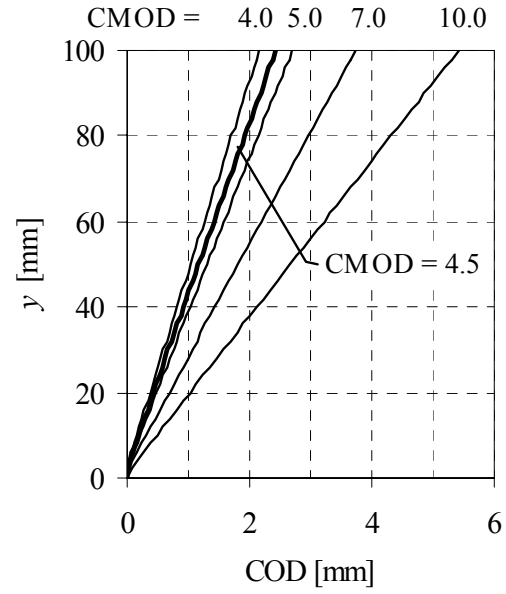

Fig. 23 The crack opening profile from FE-analysis at different $C M O D$ for the large WST specimens and Mix 4.

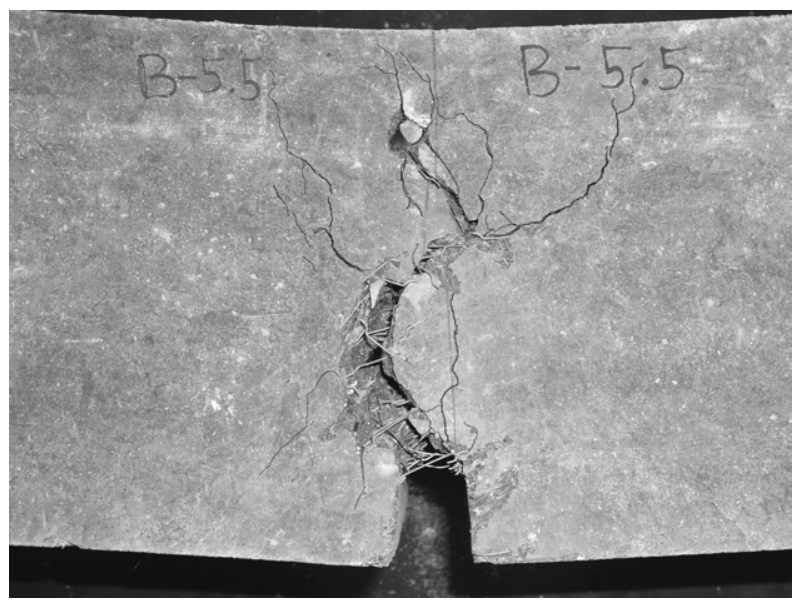

Fig. 24 Illustration of diffused cracking in beam specimen from Mix $5(\mathrm{Vf}=1.0 \%)$.

to describe the subsequent parts of the $\sigma-w$ relationship. If the tensile strength is to be predicted correctly the initial slope is important; i.e. a less steep slope has to be compensated by a lower tensile strength in order to fit the test data. That the initial slope should be steep is also based on the following observations: (1) the initial part of the $\sigma-w$ relationship is quite steep for plain concrete (see Stang 1992 and Cornelissen et al. 1986); and (2) the contribution from fibre bridging comes gradually and it is not until crack openings of at least $0.05 \mathrm{~mm}$ that it has any major influence (see Li et al. 1993). Moreover, uni-axial tension tests on fibre-reinforced concrete have also shown that the $\sigma-w$ relationship starts with an initial steep descending slope (see e.g. see Li et al. 1993 and Barragán 2002). The shape of the determined $\sigma-w$ relationships and their tendencies regarding the effect of the fibre volume fraction and w/b-ratio are comparable with results found in the literature (see for example Li et al. 1993 and Barragán 2002). However, a direct comparison is not possible due to variations in fibre content and different mix compositions. 
For the WST method two different specimen sizes were investigated using two different fibre lengths. The result of this study - the fibre orientation, the scatter in the test results, and the determined $\sigma-w$ relationships indicate that the two WST specimen sizes are comparable for both the investigated fibre lengths. However, a common recommendation is that the outer dimensions of the specimen should be at least two to three times the fibre length to reduce the wall effects (see Soroushian and Lee, 1990, and Kooiman, 2000). Moreover, it is also beneficial to have a larger fracture surface as this reduces the scatter, which results of a previous investigation (see Löfgren 2004) also indicated. Based on this, it is suggested that: (1) the outer dimension of the specimen should be at least 3 times the fibre length and/or 5 times the maximum aggregate size; and (2) that the length of the ligament should be at least 1.5 times the fibre length and/or 5 times the maximum aggregate size.

\section{Conclusions and recommendations}

The results from this study suggest that the wedge splitting test method could very well be used as a fracture test for steel fibre-reinforced concrete, and that through inverse analysis it is possible to determine the $\sigma-w$ relationship. Regarding the inverse analyses, the poly-linear $\sigma-w$ relationship, used in the FE-analyses, shows good agreement for all the specimens while the bi-linear $\sigma-w$ relationship gives good agreement for the mixes with 0.5 vol-\% fibres. For large crack openings (1.0 to $1.5 \mathrm{~mm}$ ) both methods produce similar results, whereas the bi-linear relationship is not capable of predicting the first part of the $\sigma-w$ relationship (crack openings less than 0.5 $\mathrm{mm})$.

The major factor contributing to the differences and variation in the test results and the determined $\sigma$-w relationships is believed to be related to the variation in the number of fibres across the fracture plane; the coefficient of variance was up to $30 \%$ (see Fig. 10(b)). The variation in fibre content makes an exact comparison of the $\sigma-w$ relationships difficult; however, taking this into account it seems as the 3PBT gives slightly higher post-cracking stresses (see Fig. 17 to Fig. 21).

Regarding recommendations on specimen sizes to for the WST-method more research may be needed. However, the findings of this study and previous investigations (see Löfgren, 2004) indicates that for fibres with a length less than $60 \mathrm{~mm}$ a $200 \mathrm{~mm}$ specimen could be sufficient, while a $150 \mathrm{~mm}$ specimen may be used for fibres shorter than $40 \mathrm{~mm}$. These specimen sizes should be comparable to the 3PBT according to RILEM TC 162-TDF (2002a) and the uni-axial tension test according to RILEM TC 162-TDF (2001). Furthermore, when testing steel fibre-reinforced concrete it is recommended to use a guide notch as this corresponds well to the situation in an uni-axial tension test with notches, it also prevents horizontal cracks from occurring for high fibre volume fractions. For the WST method, when deter- mining a $\sigma-w$ relationship up to a crack opening of $2 \mathrm{~mm}$ it is recommended that the test should not be ended until a $C M O D$ of at least $7 \mathrm{~mm}$ is reached; at this $C M O D$ the crack width at half the specimen height is $2 \mathrm{~mm}$ and should thus provide adequate precision a representative result.

In conclusion, the benefits of the WST method are that it does not require any sophisticated testing equipment and standard cube specimens can be used. Moreover, since the specimen is smaller, less concrete is needed to perform a test; four $150 \mathrm{~mm}$ cube specimens equal one beam specimen. However, a drawback of the WST method is that quantitative evaluation of the test result is more complicated than for the UTT, which can be interpreted directly. On the other hand, through inverse analysis it is possible to determine a $\sigma$ - $w$ relationship that can be used for structural design. However, difference in fibre orientation between test specimens and structural elements needs to be addressed if a $\sigma-w$ relationship obtained from inverse analysis is to be used for structural design.

\section{References}

ACI Committee 544. (1988). "Measurement of properties of fiber reinforced concrete." ACI Materials Journal, 85, 583-593.

ASTM C 1018. (1992). "Standard test method for flexural toughness and first crack strength of fiber-reinforced concrete (Using beam with Third-point loading)." ASTM C 1018-92, ASTM Annual Book of Standards, Vol. 04.02, ASTM Philadelphia, U.S.A., 510-516.

Barr, B., Gettu, R., Al-Oraimi, S. K. A. and Bryars, L. S. (1996). "Toughness measurement - the need to think again." Cem. \& Concrete Composites, 18, 281-297.

Barragán, B. E. (2002). "Failure and toughness of steel fiber reinforced concrete under tension and shear." Ph.D. Thesis, Universitat Politécnica de Catalunya, Barcelona, Spain.

Bolzon, G., Fedele, R. and Maier, G. (2002). "Parameter identification of a cohesive crack model by Kalman filter." Comput. Methods Appl. Mech. Eng., 191(2002), 2847-2871.

Brühwiler, E. and Wittmann, F. H. (1990). "The wedge splitting test, a new method of performing stable fracture mechanics test." Eng. Fracture Mech., $35(1 / 2 / 3), 117-125$.

Cornelissen, H. A. W., Hordijk, D. A. and Reinhardt, H. W. (1986). "Experimental determination of crack softening characteristics of normal and lightweight concrete." Heron, 31, 2 (1986).

Dupont, D. (2003). "Modelling and experimental validation of the constitutive law $(\sigma-\varepsilon)$ and cracking behaviour of fibre reinforced concrete." Ph.D. Thesis, Katholieke Universiteit Leuven.

Elser, M., Tschegg, E. K., Finger, N. and Stanzl-Tschegg, S. E. (1996). "Fracture Behaviour of Polypropylene-Fibre Reinforced Concrete: an 
experimental investigation." Comp. Science and Technology, 56, 933-945.

Gopalaratnam, V. S. and Gettu, R. (1995). "On the characterization of flexural toughness in fiber reinforced concretes." Cem. \& Concrete Composites, 17, 239-254.

Hillerborg, A., Modeer, M. and Petersson, P. E. (1976). "Analysis of crack formation and crack growth in concrete by means of fracture mechanics and finite elements." Cem. and Concrete Research, 6, 773-782.

Hillerborg, A. (1980). "Analysis of fracture by means of the fictitious crack model, particularly for fibre reinforced concrete." The Int. J. Cem. Comp., 2, 177-184.

Kim, J.-K. and Kim, Y.-Y. (1999). "Fatigue crack growth of high-strength concrete in wedge-splitting test." Cem. and Concrete Research, 29, 705-712.

Kitsutaka, Y. (1995). "Fracture parameters of concrete based on poly-linear approximation analysis of tension softening diagrams." In: Fracture Mechanics of Concrete Structures, Ed. Wittman, F. H., Aedificatio Publisher, Freiburg, Germany, 199-208.

Kitsutaka, Y. (1997). "Fracture parameters by polylinear tension-softening analysis." J. of Eng. Mechanics, 123(5), 444-450, 1997.

Kooiman, A. G. (2000). "Modelling steel fibre reinforced concrete for structural design." Ph.D. Thesis, TU Delft 2000.

Krenchel, H. (1975). "Fibre spacing and specific fibre surface." In: Fibre-Reinforced Cement and Concrete, edited by Neville, The Construction Press, UK, 69-79.

Leite, J. P. de B., Slowik, V. and Mihashi, H. (2004). "Mesolevel models for simulation of fracture behaviour of fibre reinforced concrete." In: Fibre-Reinforced Concrete, Proceedings of the Sixth International RILEM Symposium, eds. di Prisco et al., 799-808.

Li, V. C., Stang, H. and Krenchel, H. (1993). "Micromechanics of crack bridging in fibre-reinforced concrete." Materials and Structures, 26(1993), 486-494.

Linsbauer, H. N. and Tschegg, E. K. (1986). "Fracture energy determination of concrete with cube shaped specimens." Zement und Beton, 31, 38-40.

Löfgren, I. (2004). "The wedge splitting test - a test method for assessment of fracture parameters of FRC?" In: Fracture Mechanics of Concrete Structures, FRAMCOS-5, eds. Li et al. , 1155-1162.

Meda A., Plizzari G. A. and Slowik V. (2001). "Fracture of fiber reinforced concrete slabs on grade." In: Fracture Mechanics of Concrete Structures, FRAMCOS-4, ed. De Borst et al., 1013-1020.

Nanakorn, P. and Horii, H. (1996). "Back analysis of tension-softening relationship of concrete." $J$. Materials, Conc. Struct., Pavements, 32(544), 265-275.

Nemegeer, D., Vanbrabant, J. and Stang, H. (2003). "Brite euram program on steel fibre concret subtask: durability: Corrosion resistance of cracked fibre reinforced concrete." In: Test and Design Methods for Steel Fibre Reinforced Concrete - Background and Experiences, Proceedings of the RILEM TC 162-TDF Workshop, eds. Schnütgen and Vandevalle, 1996: 47-66.

Olesen, J. F. (2001). "Fictitious crack propagation in fibre-reinforced concrete beams." Journal of Eng. Mech., 127(3), 272-280.

Planas, J., Guinea, G. V. and Elices, M. (1999). "Size effect and inverse analysis in concrete fracture." International Journal of Fracture, 95, 367-378.

Que, N. S. and Tin-Loi, F. (2002). "Numerical evaluation of cohesive fracture parameters from a wedge splitting test." Engineering Fracture Mechanics, 69, 1269-1286.

RILEM TC-50 FMC (1985). "Determination of the fracture energy of mortar and concrete by means of three-point bend tests on notched beams." Materials and Structures, 18(106), 285.

RILEM TC 162-TDF (2000). " $\sigma-\varepsilon$ Design Method." Materials and Structures, 33, 75-81.

RILEM TC 162-TDF (2001). "Test and design methods for steel fibre reinforced concrete. Recommendations for uni-axial tension test." Materials and Structures, 34, 3-6.

RILEM TC 162-TDF (2002a). "Test and design methods for steel fibre reinforced concrete. Bending test - Final Recommendation." Materials and Structures, 35, 579-582.

RILEM TC 162-TDF (2002b). "Design of steel fibre reinforced concrete using the $\sigma-\mathrm{W}$ method - principles and applications." Materials and Structures, 35, 262-278.

Roelfstra, P. E. and Wittmann, F. H. (1986). "Numerical method to link strain softening with failure of concrete." In: Fracture Toughness and Fracture Energy of Concrete, Elsevier, 163-175.

Rokugo, K., Iwasa, M., Seko, S. and Koyanagi, W. (1989). "Tension-softening diagrams of steel fiber reinforced concrete." In: Fracture of Concrete and Rock, Recent Developments, Eds. Sha, S. P., Swartz, S. E. and Barr, B., Elsevier, New York, 513-522.

Romualdi, J. P. and Mandel, J. A. (1964). "Tensile strength of concrete affected by uniformly distributed and closely spaced short lengths of wire reinforcement." ACI J. Proc. 61(6), 657-671.

Soroushian, P. and Lee, C-D. (1990): Distribution and orientation of fibers in steel fiber reinforced concrete, ACI Material Journal, 87(5), 433-439.

Sousa, J. L. A. O, Gettu, R. and Barragán, B. E. (2002). "Obtaining the $\sigma-\mathrm{w}$ curve from the inverse analysis of the notched beam response." In: Annex D of Barragán, B. E. (2002). "Failure and toughness of steel fiber reinforced concrete under tension and shear." $\mathrm{Ph} . \mathrm{D}$. Thesis, Universitat Politécnica de Catalunya, Barcelona, Spain.

Stang, H. (1992). "Evaluation of properties of 
cementitious fiber composite materials." In: High Performance Fibre Reinforced Cement Composites, Vol. 1. Eds. H. W. Reinhardt and A. E. Naaman. E \& FN Spon, London, 388-406.

TNO Building and Construction Research (2002). "DIANA Finite Element Analysis User's Manual release 8.1." Eds. Frits C. de Witte and Gerd-Jan Schreppers. Delft, The Netherlands.

Trunk, B., Schober, G. and Wittmann, F. H. (1999). "Fracture mechanics parameters of autoclaved aerated concrete." Cem. and Concrete Research, 29, 855-859.

Uchida, Y., Kurihara, N., Rokugo, K. and Koyanagi, W. (1995). "Determination of tension softening diagrams of various kinds of concrete by means of numerical analysis." In: Fracture Mechanics of Concrete
Structures, FRAMCOS-2, ed. F. H. Wittmann, 17-30.

Uchida, Y. and Barr, B. I. G. (1998). "Tension softening curves of concrete determined from different test specimen geometries, In: Fracture Mechanics of Concrete Structures, FRAMCOS-3, eds. Mihashi, H. and Rokugo, K., Aedificato Publisher, Freiburg, Germany, 387-398.

Østergaard, L. (2003). "Early-Age fracture mechanics and cracking of concrete - Experiments and modelling." Ph.D thesis, Department of Civil Engineering, Technical University of Denmark.

Østergaard \& Olesen (2004). "Comparative study of fracture mechanical test methods for concrete." In: Fracture Mechanics of Concrete Structures, FRAMCOS-5, eds. Li et al., 455-462. 